\title{
EMBEDDING LIBRARIANS IN ENGINEERING PROGRAMS: THREE CASE STUDIES WITH ENGINEERING STUDENTS
}

\author{
Rachel Figueiredo', Helen Power ${ }^{2}$, Kate Mercerl, and Matthew Borland ${ }^{3}$ \\ ${ }^{1}$ Library, University of Waterloo, ${ }^{2}$ Library, University of Saskatchewan, ${ }^{3}$ Systems Design Engineering, University of
} Waterloo

rachel.figueiredo@uwaterloo.ca, helen.power@usask.ca, kmercer@uwaterloo.ca, mjborland@uwaterloo.ca

Abstract - As the information landscape becomes increasingly complex, librarians must adapt accordingly. With information so readily available, students overestimate their research skills and lack awareness of how the library can help. However, librarians' academic training makes them ideal resources to support students' complex information needs - whether students know it or not. In this paper, we argue that embedded librarianship is the solution to this disconnect between librarian and user. Specifically, this paper provides case studies at two Canadian universities of librarians approaching embedded librarianship from different directions. At the University of Waterloo, two engineering librarians worked toward an embedded model of librarianship where this was not yet an established model in the Faculty of Engineering. At the University of Saskatchewan, a librarian was hired with the intention of the new position being embedded, without a formal structure or precedent for this within the College of Engineering.

The term "embedded librarian" describes a service model where an academic librarian participates in an academic course or program on a continuing basis in order to understand the learning objectives and determine which resources best support them. In order to "do this, the librarian has to be familiar with the work and understand the domain and goals. Doing this, the librarian becomes an invaluable member of the team" [1]. The variables associated with embeddedness include location, funding, management and supervision, and participation [1]. To this end, the authors explore how each of these variables contribute to the success of moving towards this embedded model: how moving out of the library influences overall connection, how they acquired funding to grow a new collection, how management supports the overall goal, and how sustained participation in the program grows new opportunities.

At both universities, librarians have seen most success embedding in programs with a strong emphasis on integrated STEM education where the focus is on providing real-world context with the aim

CEEA20; Paper 98

Concordia University and McGill University;

June $18-21,2020$ of graduating well-rounded engineers [2]. The

authors will discuss how programmatic learning

outcomes and trends in integrated and

interdisciplinary education have allowed them to stretch beyond the traditional boundaries of academic librarianship to demonstrate value to the Engineering departments in new ways.

This paper reports on the experiences, advantages, and lessons learned in moving toward this model, and provides concrete examples for adapting these concepts to programs at other institutions. Through an intrinsic case study [3] the authors aim to understand how librarians' embeddedness can adapt and change to support student learning in different contexts. This session is targeted towards practicing engineering librarians and engineering faculty members and educators. Attendees will leave the session with ideas on how to stimulate new partnerships between their library and Engineering programs.

Keywords: embedded librarian, academic librarian, integrated education, interdisciplinary education

\section{Introduction}

As the information landscape becomes increasingly complex, librarians must adapt accordingly. With information so readily available, students overestimate their research skills and lack awareness of how the library can help. However, librarians' academic training makes them ideal resources to support students' complex information needs - whether students know it or not. In this paper, we argue that embedded librarianship is the solution to this disconnect between librarian and user. Specifically, this paper provides three case studies from two Canadian universities of librarians approaching embedded librarianship from different directions. At the University of Waterloo (Waterloo), two engineering librarians worked toward an embedded model of librarianship where this was not yet an established model in the Faculty of Engineering. At the University of Saskatchewan 
(USask), a librarian was hired with the goal of the new position being embedded, without a formal structure or precedent for this within the College of Engineering.

Waterloo's campus culture is rooted in academic rigour and cooperative education-based work experience, especially in the Faculty of Engineering, which is highly competitive from admittance through to graduation. Engineering students are an insular group on campus: students proudly identify by their home department and spend the majority of their time in the dedicated engineering buildings. Waterloo's Davis Centre Library, which is STEM-focused, is located close to these buildings. However, historically, if students ventured to the library for study space they rarely asked for research help beyond a directional-level question. Librarians recognized an opportunity to better support engineers throughout the research process. For the purposes of this paper, research refers largely to secondary research, and encompasses both traditional and non-traditional academic sources that support evolving areas of research and dissemination. With research as the central message, embedded librarianship became the mechanism to deliver it.

At the University of Saskatchewan, there is an emphasis on community and graduating contributing members to society, as many undergraduate and graduate students come from the surrounding area. Within the College of Engineering, there is an emphasis on academic rigour, and a push to recruit international students. Historically, the Engineering Library was primarily comprised of book stacks, but three years ago most of the physical collection was moved out of the library, and the physical space was repurposed as an area for collaborative learning. The library is no longer viewed as a depository for books, but as a place that fosters learning and the development of skills required for academic success. In recent years, the College of Engineering did not have a designated liaison librarian, and requests for classes and research consultations were fielded by the Science Librarians. The Engineering Librarian was hired late 2019, with the intent that this position would provide more than was previously offered. Currently, the College of Engineering is undergoing a first-year curriculum redesign, with the goal of becoming a leader in engineering education in Canada. This provides opportunities for collaboration, and the librarian can become a more active participant in student learning within this unit.

At both universities, librarians have seen most success embedding in programs with a strong CEEA20; Paper 98 Concordia University and McGill University; June $18-21,2020$ emphasis on integrated STEM education where the focus is on providing real-world context with the aim of graduating well-rounded engineers [2]. The authors will discuss how programmatic learning outcomes and trends in integrated and interdisciplinary education have allowed them to stretch beyond the traditional boundaries of academic librarianship to demonstrate value to the Engineering departments in new ways.

\subsection{Literature Review}

"Embedded librarianship" is a term that has gained traction in academic libraries since the early 2000s [4]. However, the concept itself dates back to the 1970s when medical librarians became embedded within teams alongside other health care professionals [1].

The term "embedded" can be broadly defined as librarians becoming members of the units they serve in order to better understand and meet their needs. In his seminal paper, David Shumaker identifies the four variables that are associated with being embedded: location, funding, management/supervision, and participation [1]. In academia, embedded librarianship is a service model where an academic librarian participates in a course or program on a continuing basis in order to understand the learning objectives and determine which library resources best support them. In order to do this, "the librarian has to be familiar with the work and understand the domain and goals. Doing this, the librarian becomes an invaluable member of the team" [1].

Embedded librarianship holds more opportunities for engaging students than the traditional library service model. The embedded librarian is uniquely placed to form partnerships in teaching and research, to customize services based on student needs, and to anticipate future needs, rather than the previous "responsive" methods of traditional librarianship [5].

Many librarians have been shifting away from "one-shot" information literacy sessions, where they are invited to a classroom to deliver a single session designed to teach students everything they need to know. With the embedded model, the librarian's understanding and ability to contribute to course outcomes is enhanced due to communication, collaboration, and even involvement in course or program design.

The embedded librarianship approach offers the opportunity for more meaningful collaboration with teaching faculty through a variety of factors, including location, socialization, flexibility, increased 
communication [4] and relationship building [6]. As a member of the unit, the embedded librarian can contribute fully to student education.

\subsection{Methods}

This paper outlines three distinct case studies at two Canadian universities to explore how these librarians approach an embedded librarianship model in their work. Through an intrinsic case study [3] the authors aim to understand how librarians' embeddedness can adapt and change to support student learning in different contexts. To this end, this paper reports on the experiences, advantages, and lessons learned in moving towards this model. While it provides concrete examples for adapting these concepts in programs at other institutions, the aim is not to create a guide on how to become embedded, but rather to explore how the emerging themes outlined below provide context for differing approaches to embedded librarianship.

\section{EMERGENT THEMES IN CASE STUDY}

As stated, the variables Shumaker associated with embeddedness are location, funding, management and supervision, and participation [1]. Following the initial identification of these themes, the authors of this paper completed an inductive analysis to explore how each of these variables contribute to the success of moving towards an embedded model: how moving out of the library influenced overall connection, how they acquired funding to grow a new collection, how management supports the overall goal, and how sustained participation in the program grows new opportunities.

\section{RESULTS AND DISCUSSION}

\subsection{Systems Design Engineering at Waterloo}

Waterloo's Systems Design Engineering (SYDE) department was established 50 years ago, and is known for being flexible and interdisciplinary, with roughly 700 students in the undergraduate program $[7,8]$. The program "covers technical, environmental, socioeconomic and political aspects of the engineering process using systems design methodology" [7, 8], and gives students the ability to apply their learning outside the classroom through co-op placements. In 2016, a new Librarian began working with SYDE, with a goal of building disciplinary connections around research and critical appraisal with the faculty. The Librarian was CEEA20; Paper 98

Concordia University and McGill University; June $18-21,2020$ concurrently completing her $\mathrm{PhD}$ in collaboration with one of the SYDE faculty members, and had strong relationships on which to build new partnerships and collaborative ideas.

When the SYDE Librarian began, she noticed a disconnect between terminology frequently used within the library and within the Faculty of Engineering. In response, the Librarian changed the terminology she used to communicate an important topic - "information literacy" - to "critical appraisal", which better aligns with ideas in the user-centered design process which is the backbone of the Systems Design degree [9]. This change occurred due to the Librarian developing an intimate understanding of the SYDE program and her ability to translate library terminology in more readily relatable ways to students. At a higher level, the SYDE Librarian made links between the CEAB graduate attributes and where they connected to critical appraisal. For example, "3.1.2 Problem analysis: An ability to use appropriate knowledge and skills to identify, formulate, analyze, and solve complex engineering problems in order to reach substantiated conclusions" [10] relates to critical appraisal by encouraging students to consult information sources in order to fully understand their situations of concern. Similarly, "3.1.8 Professionalism: An understanding of the roles and responsibilities of the professional engineer in society, especially the primary role of protection of the public and the public interest" [10] relates to the ethical use of information and their professional responsibilities to find and use the best information to make decisions. The SYDE Librarian worked closely with faculty members to continually improve and refocus the support she can offer around achieving $\mathrm{CEAB}$ attributes in the undergraduate program.

Librarian participation in SYDE has been a scaled and iterative approach, working together with faculty to best meet their goals. Since 2016, the SYDE Librarian has built partnerships with faculty members who were looking to include more research and critical appraisal into their courses, beginning with participation in the final year capstone projects. She worked with the faculty member in charge of capstone projects to make research a habit, rather than a one-off, helping students navigate the secondary research needed to complete their capstone projects successfully. Effectively managing this mindset shift has been core to the collaboration between the Librarian and faculty member, and requires the Librarian's sustained participation throughout the program to ensure a contextual understanding of how students' approach to information retrieval is changing over time. Building 
off this capstone participation, design courses in earlier terms were identified as another avenue where the Librarian could partner with the faculty member to encourage the SYDE students to systematically approach research and critical appraisal as foundational to learning design.

The SYDE Librarian was invited to participate in one design centered on designing for disabilities. Rather than instruct on critical appraisal, the Librarian was called upon for her experience conducting research with human participants. She created a lesson on interview etiquette and how to be sensitive around diverse populations, incorporating aspects of her library training - such as conducting reference interviews - with elements of her science-based $\mathrm{PhD}$. This is one example of how professional expertise and personal experience can combine to help move beyond the typical "librarian" box and into a place where skills and needs align.

Through collaboration, the SYDE Librarian's participation has rapidly grown, both in courses and in the program overall. The SYDE Librarian has co-supervised capstone teams; participated in in-classroom consultations, project critiques, and non-library focused workshops; and led the above-mentioned seminar on how to interview vulnerable populations. Students in the capstone design courses meet the SYDE Librarian for 1:1 meetings once per semester to discuss their situation of concern and talk about potential research that can support their projects. The location of these meetings plays a key role in the success of the embedded librarianship model. The Librarian makes a concerted effort to meet students in their home buildings, especially during their first years in the program. Through sustained interactions, students grow more comfortable with the SYDE Librarian and are resultantly more apt to meet her in her office within the library.

\subsection{Entrepreneurship at Waterloo}

In 2014, the Waterloo Library established a new liaison librarian portfolio for Entrepreneurship. "Entrepreneurship is one of the fastest growing areas on academic campuses in Canada and the United States" [11] and the development of an Entrepreneurship Librarian role at the University of Waterloo follows a trend to support this growing specialization in academia. The Entrepreneurship Librarian provides support for both curricular and cocurricular entrepreneurship programs [12]; however, the most engaged stakeholders come from the Conrad School of Entrepreneurship and Business (Conrad) which is housed in the Faculty of Engineering.
Students can take a number of specialized courses, co-op offerings, or a Minor in Entrepreneurship through Conrad during their undergraduate degrees, and roughly 60 students are enrolled in the Master's of Business, Entrepreneurship, and Technology (MBET) program each year. Conrad's programs bridge classroom teachings with experiential learning in an effort to "empower students to launch and lead the development of new ideas in both startup and corporate contexts" [13]. To this end, the Entrepreneurship Librarian aims to support students in their endeavours to make an impact, whether as entrepreneurs or intrapreneurs.

In establishing this liaison specialization, determining the library's niche within the broad entrepreneurship ecosystem on campus was a considerable task. Naturally, research plays an integral role in the support the Entrepreneurship Librarian provides, and providing access to relevant collections is key. There is no collections fund for Conrad, and there were no existing funds for Entrepreneurship collections when this role was established. While Waterloo has Business + Your Major programs [14], it does not have a business school. In turn, the library historically did not provide access to many of the typical resources used within these programs which may have been leveraged by entrepreneurship programs. Researchers frequently requested access to resources that would help with market and industry research, specifically for privately-owned companies and niche or emerging markets. Through consultations with students and faculty, it became clear that the library could provide the most value to this community by developing a collection to support these distinctive research needs. Within the library, the Entrepreneurship Librarian championed new collections funding to support this area. The Librarian built a case that the recommended resources were an investment in the library's commitment to the campus goal of leading entrepreneurship education, practice, and research, as outlined in the University's Strategic Plan [15]. Innovation is deeply embedded into University of Waterloo's cultural identity, and deliberately collecting resources to support innovation and entrepreneurship demonstrates how the library can support both academic and experiential studies. A written report was sent to the library's upper administration, which included testimonials from key stakeholders describing the existing gaps in their research and outlining their need for specific resources. The library ultimately allocated funds for an Entrepreneurship and Business collection, with a goal of continually refining the collection to reflect emerging areas in research and practice.

CEEA20; Paper 98

Concordia University and McGill University;

June $18-21,2020$ 
Outside the library, the development of this report was a way to build inroads with the Conrad community. By championing these new collections, the Librarian demonstrated awareness and interest in these researchers and provided opportunities for their voices to feel heard. In turn, these collections became a mechanism to further embed the Librarian into Conrad programs. In the early years of the Entrepreneurship specialization, the Librarian participated in very few courses, and consulted with few students for research appointments. As access to subscription-based resources increased, the Librarian has seen increased engagement through instruction and research consultations. While the Entrepreneurship Librarian is regularly available for appointments within the library, she began weekly office hours in the Conrad School's open meeting space for drop-in appointments. Meeting users in their own space allowed for serendipitous connections and has led to opportunities for student coaching, committee participation, and research collaboration. These opportunities would not have been possible had the Librarian stayed within the confines of the physical library building, and demonstrate the importance of location in the embedded librarian model.

\subsection{The College of Engineering at University of Saskatchewan}

USask's College of Engineering (the College) was established in 1912, making it one of Canada's oldest schools for engineering [16]. The College aims to graduate well-rounded engineers. The Ron \& Jane Graham School of Professional Development was founded in 2012, and it offers unique opportunities with the goal of setting USask students apart [17]. This includes courses in leadership, communication, and writing, and programs such as the Certificate in Professional Communication and the Technological Innovation Certificate.

In 2019, the University Library hired a librarian with the intent of this position being "embedded" within the College of Engineering. Administration within Engineering were eager to explore this new facet of librarianship. While the University already had a librarian embedded in the College of Agriculture and Bioresources, there was no set framework for what "embedded" meant. This autonomy enabled the Engineering Librarian to initiate an ongoing environmental scan to identify the needs for individual departments, programs, and courses within the College.

CEEA20; Paper 98

Concordia University and McGill University;

June $18-21,2020$
When the Engineering Librarian first arrived at the university, her office was immediately located among the faculty in the engineering building. This has aided to cement her position as a colleague, and has increased her visibility within the College. This closeness to the faculty has provided ample opportunities, from brief conversations in the line for the printer to deeper connections through attendance at meetings. These continued conversations paved the way for a variety of opportunities that may not otherwise have presented themselves, including collaborations in teaching and research.

Being physically present in the College enables for contributions to teaching and curriculum design. Consultations with professors allow for the incorporation of course-level learning outcomes into class visits, so that these library sessions are built seamlessly into the curriculum, building off previous classes and providing skills necessary for design projects. The College is presently undergoing a firstyear curriculum redesign. The Engineering Librarian is collaborating with the team to incorporate information literacy skills into three of the courses, which provides an opportunity to teach more robust concepts since learning outcomes for each course build off each other.

While the Engineering Librarian position and the collection are funded by the University Library, the College is greatly invested in what the money is used for. There is a collections fund for the College of Engineering as a whole, which is used for the purchase of print and electronic resources.

Because of the unique nature of the USask being one of the only universities in the province, there is significant support and investment from alumni. Members of the Association of Professional Engineers and Geoscientists of Saskatchewan (APEGS) have alumni-like privileges, which enables them to access University Library resources. APEGS is also highly invested in the quality of education at the university, and there is a substantial annual donation to the Engineering Collections fund. As such, the appropriate use of and communication about these funds is critical in relationship building with the College as a whole.

The Librarian position is funded and supervised by the library, but the Librarian is embedded within the College of Engineering. The disconnect between the location of the work being done and the supervision being in different university units is eased by regular communication. The Librarian has biweekly meetings with the Associate Dean of the University Library, to discuss projects, collaborations, and opportunities within the College of Engineering. 


\section{DISCUSSION}

The information landscape is changing, and with it how students access, use, navigate, and understand an often overwhelming amount of information. Meeting our users where they are - in terms of language used, concepts taught, and physical location - helps to shed light on librarians to a population who deems the role ever more irrelevant or opaque. In the SYDE case study, the Librarian effectively moved away from teaching how to use subscription-based academic databases to teaching why they are used; providing context for students who might otherwise dismiss an isolated workshop on database searching. In the Conrad example, the impetus to use subscription resources was somewhat embedded: students recognized the need for market research reports and were often met with paywalls when trying to access them. The librarian's task then became making a case for why an academic library should purchase licenses to these non-traditional sources. In the USask case study, the Engineering Librarian is building connections with teaching faculty in order to make library sessions as relevant as possible to students given their point of need and the information literacy skills required for their assignments and future practice. Among all the case studies, the overarching theme is the desire to align themselves as members of the department(s) they serve, advocating for the needs of the engineering departments within the library, and promoting the librarians' areas of expertise within the engineering departments.

In each of the above case studies, there was no existing model for embedded librarianship within these departments. Rather, each librarian attempted to adopt the model, recognizing that it can allow for more consistent and engaging interactions with the populations we serve. Embeddedness itself is not the goal, however it can provide a mechanism for keeping the librarian front-of-mind when opportunities for instruction, consultations, and outreach arise.

Some of the success in these case study examples can be attributed to the fact that each department has a heavy focus on integrated education and professionalism. For students in these programs, the goal shifts from just doing well on an assignment to learning content that will benefit them well beyond their academic careers. Through co-op placements, start ups, and other experiences working in industry, students are often asked to do some sort of information retrieval [18] and thereby internalize an understanding about the value of the resources

\section{CEEA20; Paper 98}

Concordia University and McGill University;

June $18-21,2020$ librarians often promote. Engineering practice has a fundamental expectation of due-diligence and technical competency that requires decision making to be well-supported and well-researched. This can be a fruitful foundation for the embedded librarian model when librarians are invited to share their information expertise in a myriad of courses throughout a program.

Of the four emergent themes, the most notable in this paper is location. While embedded librarians may hold office space within the departments they serve, such as the example with USask, it is possible to move toward an embedded model without having an office in the same building. The key is being present when possible. Simple acts, like walking to the engineering building to buy coffee, can result in unexpected connections that may lead to greater involvement down the road. And more concerted efforts, like holding office hours in a building, are often met with enthusiasm. Identifying and developing relationships with key allies in the Engineering departments can also be important, as the possible role and the contribution of the Librarian may not be understood by the target department.

While each case study highlights successes in this model, each librarian has also spent considerable time on tasks that do not explicitly require their specialized knowledge and training. However, many of these efforts are realized through serendipitous opportunities that would not otherwise be possible had the librarian been out of sight, out of mind. This shift necessitated top-down support from senior management who allowed us freedom to explore opportunities without requiring immediate tangible results. In terms of the management/supervision theme, support can be both passive and impassive. Management can provide outright support through acts like approving collection requests, but also more simply by allowing librarians to explore a new model without fear of failure. The move towards an embedded model takes time, and admittedly none of the above case studies are examples of a final product, but through sustained interactions with the departments we serve we are beginning to see what is possible.

\section{CONCLUSION}

Success with embedded librarianship can take many forms. In each of the three case studies, the authors explored how four main themes location, funding, management and supervision, and participation - provide context for their work. While each example draws on elements of these themes, each example also demonstrates that fruitful collaborations with engineering departments can exist 
even when only a few of the themes are evident. Becoming truly embedded takes time, but focusing on aligning with your department can happen more readily through incremental change. The academic training and expertise of librarians makes them ideal candidates to contribute to student learning; the embedded librarianship model provides context for how their services can be effectively tailored and promoted.

\section{REFERENCES}

[1] D. Shumaker, M. Talley, and W. Miervaldis, Models of Embedded Librarianship: Final Report, Prepared under the Special Libraries Association Research Grant 2007. June, 2009.

[2] T. Kelley and G. Knowles, "A conceptual framework for integrated STEM educated", Journal of STEM

Education, vol. 3, no. 11, July 2016. DOI 10.1186/s40594016-0046-z

[3] P. Baxter and S. Jack, "Qualitative Case Study Methodology: Study Design and Implementation for Novice Researchers," The Qualitative Report, vol. 13, no. 4, pp. 544-559, 2008.

[4] K. Drewes and N. Hoffman, "Academic Embedded Librarianship: An Introduction,” Public Services Quarterly, vol. 6, no. 2-3, pp. 75-82, 2010.

[5] D. Shumaker, The Embedded Librarian: Innovative Strategies for Taking Knowledge Where It's Needed. Medford, NJ: Information Today, Inc., 2012, 212 pp. \{ISBN-978-1-57387-452-6\}

[6] M. Reale, Becoming an Embedded Librarian: Making

Connections in the Classroom. American Library Association, 2015, 104 pp. \{ISBN-978-0-8389-1367-3\}

[7] Systems Design Engineering. "Systems Design Engineering." Waterloo Engineering.

https://uwaterloo.ca/systems-design-engineering/ (accessed Feb. 1, 2020).

[8] Systems Design Engineering. "About Systems Design Engineering." Waterloo Engineering. https://uwaterloo.ca/systems-design-engineering/aboutsystems-design-engineering (accessed Feb. 1, 2020).
[9] K. Mercer, K. Weaver, R. Figueiredo and C. Carter. "Critical Appraisal: The Key to Unlocking Information Literacy in the STEM Disciplines." C\&RL News, upcoming.

[10] Engineers Canada Consultation Group on Engineering Instruction and Accreditation. "Consultation Group Engineering Instruction and Accreditation: Graduate Attributes." PDF. (https://engineerscanada.ca/sites/default/files/GraduateAttributes.pdf).

[11] C. Toane and R. Figueiredo. "Toward core competencies for entrepreneurship librarians." Journal of Business and Finance Librarianship, vol. 23, no. 1, pp. 3562, Mar. 2018. DOI: 10.1080/08963568.2018.1448675

[12] Office of Research "Entrepreneurship." University of Waterloo. https://uwaterloo.ca/entrepreneurship/ (accessed Feb. 1, 2020).

[13] Conrad School of Entrepreneurship and Business. "About the University of Waterloo Conrad School of Entrepreneurship and Business". University of Waterloo. https://uwaterloo.ca/conrad-school-entrepreneurshipbusiness/about-university-waterloo-conrad-schoolentrepreneurship-and (accessed Feb. 1, 2020).

[14] University of Waterloo. "Earn a business degree with a difference." Undergraduate Programs.

https://uwaterloo.ca/future-students/programs/business (accessed Feb. 1, 2020).

[15] University of Waterloo. "Connecting Imagination with Impact." University of Waterloo Strategic Plan 2020-2025. https://uwaterloo.ca/strategic-plan/ (accessed Feb. 1, 2020). [16] University of Saskatchewan. Why study at the U of S College of Engineering?" College of Engineering. https://engineering.usask.ca/ (accessed Feb.1, 2020).

[18] University of Saskatchewan. The Ron \& Jane Graham School of Professional Development. College of Engineering.

https://engineering.usask.ca/departments/sopd.php (accessed Feb.1, 2020).

[19] J. Jeffryes and M. Lafferty, "Gauging Workplace

Readiness: Assessing the Information Needs of

Engineering Co-op Students," Issues in Science and

Technology Librarianship, no. 69, Apr. 2012.

CEEA20; Paper 98

Concordia University and McGill University;

June $18-21,2020$ 